\section{MICE AND CELLS:}

\section{THE IMPORTANCE OF IMAGING}

Imaging is at the heart of several articles in this month's issue of BioTechniques. What makes these studies particularly interesting is the variety of ways in which imaging is applied, providing a wonderful illustration of the growing use of image acquisition and analysis technologies in today's lab.

On page 227, Filippo Piccinini and his colleagues present a new software solution for estimating the volumes of three-dimensional multicellular spheroids using light sheet microscopy. Spheroids have attracted great interest for cancer studies and drug testing, and change in spheroid volume is an important parameter for evaluating treatment effectiveness. The Reconstruction and Visualization from Multiple Sections (ReViMS) software Piccinini's group developed segments z-stacks of fluorescence images to reconstruct spheroids, providing precise and accurate volume measurements.

A slightly lower-tech imaging approach was used by Hiroshi Nishimune and his colleagues to solve the problem of tracking the behavior of mice in cages (page 215). "Mouse Behavior Tracker" is a system that combines a low-cost webcam with custom software to monitor and analyze the distance traveled, speed, and movement patterns of mice within their home cages. Using this technology, the authors compared the movements of wild-type mice to those of mice with motor abnormalities, quantitatively and in an automated fashion.

Finally, this month's Tech News feature, "Colorful Engineering" (page 200), reviews the history of fluorescent dyes and proteins and explores what the future holds for these important imaging tools. From specialized chemistries enabling fine-tuning of fluorescent dyes to unique fluorescent proteins and specialized biosensors, the toolkit for visualizing cell structures, proteins, and nucleic acids continues to grow, creating unique experimental possibilities.

These are just a few examples of how imaging is evolving to meet the needs of researchers at the lab bench. And even more innovations are sure to come, further expanding how imaging is used in the life sciences. As always, you can share your thoughts on imaging-or anything else-at bioeditor@biotechniques.com.

BioTechniques is a peer-reviewed journal dedicated to the publication of original laboratory methods, related technical tools, and methods-oriented review articles that are of broad interest to scientists engaged in basic and applied life science research. Complete Instructions for Authors are available at bt.EditorialManager.com, BioTechniques' website for online manuscript submission. All manuscripts should be submitted at this site.

\section{BioTechniques Staff}

Editorial, Production \& Circulation

Editor-in-Chief: Nathan S. Blow, Ph.D.

Managing Editor: Amy R. Volpert

Senior Editor/Commercial Editor: Patrick C.H. LO, Ph.D.

Senior Editor/News Editor: Kristie Nybo, Ph.D.

Contributing Writers:

Sarah A. Webb, Ph.D.

Production and Creative Manager,

BioScience Group: Genevieve McCarthy

Marketing Manager,

BioScience Group: Carisa McLaughlin

Sales \& Business Offices

Publisher: Cheryl Wall

Director, Operations and Audience Development,

BioScience Group: Nora Pastenkos

East Coast/Europe/Asia/Latin America: Cheryl Wall, 978-356-0032 cwall@biotechniques.com

Midwest: Bob Zander, 312-925-7648

bob.zander@informausa.com

West Coast: Kayla McCutchan, 212-652-2667

kmccutchan@biotechniques.com

Manager, Advertising and Production Services,

BioScience Group: Christine Briglia, christine.briglia@informausa.com

List Rental: Amy Miller• amiller@ibcusa.com

Reprints: biotechniques@fosterprinting.com

For subscriptions and inquiries, contact:

Phone: (847) 763-4930 Toll-free: (877) 232-2399

Email: biotechniques@halldata.com

\section{EditorialBoard}

Bill Brizzard, Indiana University Research and Technology Corp. Bruce Budowle, UNT Health Science Center

Piotr Chomczynski, Molecular Research Center

Rita R. Colwell, University of Maryland-College Park and Johns Hopkins University

Joshua J. Coon, University of Wisconsin-Madison Manel Esteller, Spanish National Cancer Centre (CNIO) Jeffrey Felton, Western University of Health Sciences Ron M. Fourney, Royal Canadian Mounted Police Ivar Giaever, Rensselaer Polytechnic Institute Richard A. Gibbs, Baylor College of Medicine Erica A. Golemis, Fox Chase Cancer Center Peter M. Gresshoff, The University of Queensland Yoshihide Hayashizaki, RIKEN

Jörg Hoheisel, German Cancer Research Center Leroy Hood, Institute for Systems Biology Paul Keim, Northern Arizona University Pui-Yan Kwok, University of California, San Francisco Rachael L. Neve, Massachusetts Institute of Technology Peter J. Oefner, University of Regensburg Stephen W. Paddock, University of Wisconsin-Madison Scott D. Patterson, Amgen, Inc.

Leonard F. Peruski, Jr., Centers for Disease Control John Quackenbush, Harvard School of Public Health Joshua Z. Rappoport, Northwestern University School of Medicine John Rossi, City of Hope

Herbert P. Schweizer, Colorado State University Jay Shendure, University of Washington Barton Slatko, New England Biolabs Steve S. Sommer, MEDomics, LLC Igor Stagljar, University of Toronto Mathias Uhlén, The Royal Institute of Technology Timothy Veenstra, SAIC-Frederick, Inc. Kent E. Vrana, Penn State College of Medicine Michael Weiner, AxioMx 